\title{
QUALIDADE NA PRESTAÇÃO DE SERVIÇOS JURÍDICOS EDUCACIONAIS: UM DIREITO FUNDAMENTAL
}

\author{
Valeria Jabur Maluf Mavuchian Lourenço ${ }^{1}$ \\ Vladmir Silveira ${ }^{2}$
}

Resumo: O direito à educação é direito humano fundamental e direito social imprescindível para o desenvolvimento do indivíduo, habilitação para o trabalho e exercício da cidadania. Nesse sentido, ressalte-se que deve ser ministrado com qualidade. Utilizando o método hipotético dedutivo e pesquisa bibliográfica, fundado no trabalho Exame de Ordem em Números, resultado da parceria entre a OAB e a FGV Projetos, pretende-se analisar a efetividade deste direito de maneira a questionar se o graduando nos cursos jurídicos tem sido contemplado com ensino de qualidade e de forma satisfatória para habilita-lo à aprovação no exame da Ordem.

Palavras-chave: Direito Humano Fundamental; Direito à Educação; Missão da Universidade; Qualidade do Ensino Jurídico; Exame OAB

\section{QUALITY IN PROVIDING LEGAL EDUCATIONAL SERVICES: A FUNDAMENTAL RIGHT}

\begin{abstract}
The right to education is a fundamental human right and social right essential to the development of the individual qualification for work and citizenship. In this sense, it is worth mentioning that should be provided with quality. Using the deductive hypothetical method and literature, founded the Order of Examination work in Numbers, a partnership between the OAB and FGV Projetos, we intend to analyze the effectiveness of this right in order to question whether the graduating in law courses has been contemplated with quality and satisfactory education to enable it to pass the bar exam.
\end{abstract}

Keywords: Fundamental Human Right; Right to Education; University Mission; Quality of

\footnotetext{
${ }^{1}$ Mestre em Direito pela Universidade Nove de Julho. Especialista em Direito do Consumidor e em Direito Público. Membro da Associação Brasileira de Direito Educacional. Pesquisadora do Núcleo de Estudos em Direito Educacional da Pontifícia Universidade Católica de São Paulo - NEDUC/PUCSP, professora e advogada. E-mail: valjabur@gmail.com

2 Pós-doutor em Direito pela Universidade Federal de Santa Catarina - UFSC (2009). Doutor em Direito pela Pontifícia Universidade Católica de São Paulo (2006). Mestre em Direito pela Pontifícia Universidade Católica de São Paulo (2003), Graduação em Direito em (1997) e Graduação em Relações Internacionais pela mesma Universidade. Professor Titular Livre da Universidade Federal de Mato Grosso do Sul. Foi Coordenador do Programa de Mestrado em Direito da UNINOVE (2011-2016). É Professor da Pontifícia Universidade Católica de São Paulo - PUC/SP. Foi Secretário Executivo (2007-2009) e Presidente (2009-2013) do Conselho Nacional de Pesquisa e Pós-Graduação em Direito - CONPEDI. Consultor ad hoc para CAPES/MEC, CNPq, FAPEMIG, FUNDECT/MS. Foi membro do Comitê da Área do Direito da CAPES/MEC (2008-2010), Comitê Técnico Científico da CAPES/MEC (2002-2005) e Conselho Superior da CAPES/MEC (2005-2006). Foi membro da Comissão de Altos Estudos do Centro de Referência Memórias Reveladas (2011-2014). Na advocacia, tem experiência na área de Direito de Defesa do Consumidor e Direito Público, com ênfase em Direito Administrativo, Constitucional, Educacional e Tributário. Os temas de interesse em pesquisa são: Direito Internacional; Direitos Humanos e Direito Internacional dos Direitos Humanos. E-mail: vladmiracademico@gmail.com
} 
Legal Education, Bar exam

\section{Introdução}

Adotando a sistemática dos direitos humanos e a teoria dos direitos humanos fundamentais, a educação passa a ser entendida como um meio a partir do qual é possível efetivar a dignidade da pessoa humana em suas diversas matizes.

Entendida como um direito fundamental, ou seja, expresso no texto constitucional, a educação tem de ser interpretada como um instrumento apto à realização da cidadania, dos valores sociais do trabalho e do pluralismo político, fundamentos da República Federativa do Brasil, nos termos do artigo $1^{\circ}$ da Carta Magna.

Enquanto direito social, tem como objetivo promover o desenvolvimento de todas as potencialidades humanas. Neste sentido, o artigo 205 da Constituição Federal dispõe que a educação é um direito universal, destinado a todos, e um dever pluriparticipativo, que envolve ativamente o Estado, a família e a sociedade colaborativamente, de modo a promover o pleno desenvolvimento do indivíduo, ou seja, seu preparo para o exercício da cidadania e sua qualificação para o trabalho.

O artigo 206 da Constituição da República Federativa do Brasil estabelece que o ensino no país será ministrado com base em alguns princípios. Dentre os princípios estabelecidos pelo texto constitucional, o inciso VII do referido artigo prevê a "garantia de padrão de qualidade".

Neste passo, a garantia da qualidade do ensino nacional se descortina como a base fundamental que estabelece a sistemática jurídica do direito à educação. Ante este cenário, a docência revela-se como uma missão de excelência para a promoção da cidadania e dignidade dos indivíduos e para o desenvolvimento do país.

No que tange a educação de nível superior, mais especificamente, o ensino jurídico no Brasil, objeto do presente trabalho, pode-se observar, em um primeiro momento, que o pressuposto para o sucesso do bacharel é a aprovação no Exame da Ordem do Advogados do Brasil. Isto porque, sem ela, o bacharel fica impossibilitado de exercer a advocacia e, consequentemente, de participar da maioria dos concursos públicos na área jurídica, que demandam a comprovação de exercício jurídico por um período mínimo de três anos.

Por meio do método hipotético-dedutivo e pesquisa bibliográfica, o presente trabalho

Revista de Pesquisa e Educação Jurídica | e-ISSN: 2525-9636 | Brasília | v. 3 | n. 1 | p. 80 - 97 | Jan/Jul. 2017. 
procurará estudar quais os requisitos que compõem um ensino jurídico de qualidade e como podem ser verificados. Para tanto, utilizará as informações, os dados e as conclusões resultantes do trabalho "Exame da Ordem em Números", resultado da parceria entre a Ordem dos Advogados do Brasil (OAB) e a Fundação Getúlio Vargas (FGV-Projetos), responsável pela organização do Exame de Ordem Unificado desde a sua segunda edição em 2010, tendo como referência os exames unificados II a X.

O primeiro item tratará do direito fundamental à educação de qualidade, à luz do texto constitucional, bem como sobre a atividade pública educacional exercida por particulares e a expansão do ensino superior no país. O segundo item tratará sobre as missões e obrigações das instituições de ensino superior no Brasil, de modo a abranger a respeito da autonomia universitária e a responsabilidade social das mesmas. Em seguida, o terceiro item tratará da qualidade atual na prestação de serviços educacionais no campo das ciências jurídicas. Ao final, com base no referido trabalho institucional, procurar-se-á observar se atualmente os cursos de ciências jurídicas do país atendem ao princípio constitucional da qualidade.

\section{Do direito fundamental a uma educação de qualidade}

As fases do processo de evolução dos direitos humanos são frutos de lutas e conquistas ao longo da História, coincidindo com as exigências de novos direitos que, aos pouco, adensam o princípio da dignidade da pessoa humana, segundo ensinam Vladmir Oliveira da Silveira e Maria Mendez Rocasolano 3 .

Em seu processo evolutivo, propõe contínuo amoldamento do direito às necessidades atuais e futuras, trazendo o reconhecimento de novos direitos, bem como sua inclusão na ordem constitucional.

Por meio dele, possibilitou-se a expansão conceitual do valor da dignidade da pessoa humana, consubstanciada em dimensões de direitos humanos associadas a valores preponderantes a um determinado momento histórico. Assim, os direitos humanos podem ser classificados como: direitos individuais, direitos sociais, direitos prevendo relações econômicas, direitos fundados nas relações políticas e os decorrentes de tratados e convenções internacionais.

O presente trabalho traz o recorte sobre o direito à educação, direito social de

\footnotetext{
${ }^{3}$ SILVEIRA, Vladmir Oliveira da; ROCASOLANO, Maria Mendez. Direitos Humanos: conceitos, significados e funções. São Paulo: Saraiva. 2010, p. 142-143.
}

Revista de Pesquisa e Educação Jurídica | e-ISSN: 2525-9636 | Brasília | v. 3 | n. 1 | p. 80 - 97 | Jan/Jul. 2017. 
profunda relevância na construção da sociedade, e, que exerce papel fundamental para promoção dos direitos humanos. Tal fato que se depreende do preâmbulo da Declaração Universal de Direitos Humanos ${ }^{4}$ :

\begin{abstract}
A Assembleia Geral da ONU proclama a presente Declaração Universal dos Diretos Humanos como o ideal comum a ser atingido por todos os povos e todas as nações, com o objetivo de que cada indivíduo e cada órgão da sociedade, tendo sempre em mente esta Declaração, se esforcem, através do ensino e da educação, por promover o respeito a esses direitos e liberdades, e, pela adoção de medidas progressivas de caráter nacional e internacional, por assegurar o seu reconhecimento e a sua observância universais e efetivos, tanto entre os povos dos próprios Estados membros, quanto entre os povos dos territórios sob sua jurisdição.
\end{abstract}

A formação por meio da educação conduz à construção do conhecimento, capacitando-o a discernir, de modo se traduzir na possibilidade de se fazer escolhas conscientes e livres. Nesse entendimento, o Comentário Geral 11 da Comissão de Direitos Econômicos e Sociais das Nações Unidas, ao tratar sobre o Pacto Internacional dos Direitos Econômicos, Sociais e Culturais, afirma que o direito à educação, reconhecido em outros tratados internacionais, é classificado como "direito econômico, direito social e direito cultural, e também, de várias maneiras, direito civil e direito político, dado que é central para a completa e efetiva realização também daqueles direitos, representando a indivisibilidade e interdependência de todos os direitos humanos ${ }^{5}$."

A educação tem profunda relevância com a concretude da dignidade da pessoa humana, pois desempenha papel formador e informador, de maneira a afirmar a identidade do indivíduo, sob viés emancipador, levando-o a compreender seu contexto na sociedade, capacitando-o a avaliar as opções para realização de suas escolhas, elucidando-o a ter sua opinião e manifestar sua vontade com clareza e autonomia como forma de expressão de sua liberdade.

Proporciona a formação da consciência do indivíduo de modo a levaá-lo a não se submeter a poderes externos que possam constrange-lo a fazer ou deixar de fazer algo, como forma de sua autodeterminação ${ }^{6}$.

\footnotetext{
${ }^{4}$ ONU - Organização das Nações Unidas. Declaração Universal dos Direitos Humanos. 10 dez. 1948. Disponível em: http://www.ohchr.org/EN/UDHR/Pages/Language.aspx?LangID=por. Acesso em: 22/11/2016

${ }^{5}$ KIM, Richard Pae. BOLZAM, Angelina Cortelazzi. Direito à educação de qualidade e seus fundamentos jurídicos. Cadernos de Direito, Piracicaba, v. 15, jul-dez 2015,p. 177. Disponível em: $<<$ http://dx.doi.org/10.15600/2238-1228/cd.v15n29p167-200>> Acesso em 22/11/2016.

${ }^{6}$ CHAUI, Marilena. Convite à Filsofia. São Paulo: Ática, 2000. p. 434.
}

Revista de Pesquisa e Educação Jurídica | e-ISSN: 2525-9636 | Brasília | v. 3 | n. 1 | p. 80 - 97 | Jan/Jul. 
O direito à educação está disposto no artigo $205^{7}$ e seguintes do texto constitucional, sendo certo que o artigo 206 traz seus princípios, como ressalta José Afonso da Silva ${ }^{8}$ :

...igualdade de condições para o acesso e permanência na escola; liberdade de
aprender, ensinar, pesquisar e divulgar o pensamento, a arte e o saber; pluralismo de
ideias e de concepções pedagógicas, e coexistência de instituições públicas e privadas
de ensino; gratuidade do ensino público em estabelecimentos oficiais; valorização
dos profissionais do ensino garantido na forma da lei; planos de carreira para o
magistério público, com piso salarial e profissional e ingresso exclusivamente por
concurso público de provas e títulos; gestão democrática; garantia de padrão de
qualidade.

A qualidade da educação é matéria de relevância pública, que condiciona ao desenvolvimento da sociedade e da atividade econômica. Ao se tratar de qualidade, abarca-se a integralidade de variáveis que compõem o fenômeno, tais como: os aspectos econômicos, pedagógicos e administrativos. É possível aplicar inclusive definições teóricas de administração empresarial, a fim de se perquirir o padrão de qualidade educacional.

Ante a competitividade do mercado globalizado, a qualificação adequada dos indivíduos revela-se essencial tanto para a sobrevivência de um determinado polo geográfico, quanto de um setor de negócios. Isto posto, pode-se observar que atualmente a prestação de uma educação de qualidade é uma necessidade almejada por todos os setores da sociedade.

Entretanto, na maioria das vezes, o poder público não consegue garantir a prestação adequada, integral e suficiente de referido direito constitucional.

A educação é um serviço público não privativo, ou seja, sua prestação não é exclusiva do Estado. Ao contrário, pode ser realizada pelo setor privado da sociedade. Contudo, ao realizarem a prestação de serviços educacionais, os particulares exercem munus público, dada a importância de sua atividade. O sistema jurídico nacional procura coadunar os aspectos da pessoa jurídica de direito privado e as especificidades de sua singular função social.

Destarte, destacada é a atividade das instituições de ensino privado no país,

\footnotetext{
${ }^{7}$ BRASIL, Constituição Federal de 1988. Disponível em: http://www.planalto.gov.br. Acesso em 03/06/2016. Art. 205. A educação, direito de todos e dever do Estado e da família, será promovida e incentivada com a colaboração da sociedade, visando ao pleno desenvolvimento da pessoa, seu preparo para o exercício da cidadania e sua qualificação para o trabalho.

Art. 206. O ensino será ministrado com base nos seguintes princípios: I - igualdade de condições para o acesso e permanência na escola; II - liberdade de aprender, ensinar, pesquisar e divulgar o pensamento, a arte e o saber; III pluralismo de idéias e de concepções pedagógicas, e coexistência de instituições públicas e privadas de ensino; IV gratuidade do ensino público em estabelecimentos oficiais; V - valorização dos profissionais da educação escolar, garantidos, na forma da lei, planos de carreira, com ingresso exclusivamente por concurso público de provas e títulos, aos das redes públicas; VI - gestão democrática do ensino público, na forma da lei; VII - garantia de padrão de qualidade; VIII - piso salarial profissional nacional para os profissionais da educação escolar pública, nos termos de lei federal.

${ }^{8}$ SILVA, José Afonso da. Curso de Direito Constitucional Positivo. Malheiros. São Paulo. 2004. p. 838
} 
caracterizada pela prestação de um serviço essencial à sociedade, que se submetem à prévia autorização administrativa e à fiscalização do poder público.

Tratando sobre o tema, o trabalho Exame de Ordem em Números, resultado da parceria entre a OAB e a FGV Projetos do ano de 2013 relata ${ }^{9}$ :

\begin{abstract}
O processo que levou a essa expansão acelerada teve como marco inicial a aprovação da nova Lei de Diretrizes e Bases da Educação Nacional, em 20 de dezembro de 1996 (LDB - Lei $n^{\circ}$. 9.394/9634). A LDB é a lei orgânica e geral da educação brasileira, estabelecendo, com base nos princípios presentes na Constituição, as diretrizes e as normas básicas para organização do sistema educacional, incluindo as obrigações que pautam a criação e organização das instituições de ensino superior (faculdades, universidades etc.).

A nova LDB, entre outros aspectos, reduziu alguns obstáculos institucionais e legais à difusão da rede privada de educação superior, permitindo, por exemplo, a criação e expansão de figuras institucionais não universitárias (como faculdades, centros universitários, faculdades integradas, institutos e centros de ensino tecnológico) que não observam o princípio da indissociabilidade entre pesquisa, ensino e extensão (característica das universidades). Com efeito, ao omitir a obrigatoriedade do princípio em seu texto, a LDB de 1996 permitiu maior liberdade e flexibilidade no estabelecimento de formas institucionais de ensino e funcionamento do sistema de ensino superior nos mais "variados graus de abrangência ou especialização" (Art.45).
\end{abstract}

Nesse sentido, observa-se que a prestação dos serviços educacionais por meio da iniciativa privada, nos termos do artigo 209 da Constituição Federal, deve submerter-se à regulação estabelecida pela Lei de Diretrizes e Bases da Educação, mediante autorização, bem como ter a qualidade de seu ensino avaliada e fiscalizada pelo Estado. Cumpre observar que, nos termos do artigo 206, III, da Constituição Federal, confere-se à iniciativa privada, concomitantemente às instituições públicas a função complementar da tarefa educacional.

Como ressaltado, a educação é um serviço público cuja prestação não é privativa do Estado, haja vista que a Constituição Federal, em seus artigos $1^{\circ}$ e $3^{\circ}$ apresenta fundamentos a fim de projetar o desenvolvimento do país, garantindo a ordem econômica e existência digna. Nesse sentido afirma Eros Roberto Grau ${ }^{10}$ :

Daí por que a preservação dos vínculos sociais e a promoção da coesão social pelo Estado assumem enorme relevância no Brasil, a ele incumbindo a responsabilidade pela provisão, à sociedade, como serviço público, de todas as parcelas da atividade econômica em sentido amplo que sejam tidas como indispensáveis à realização e ao desenvolvimento da coesão e da interdependência social.

A relevância do sistema privado da educação consiste nos objetivos do desenvolvimento da pessoa humana, no preparo para o exercício da cidadania e na

${ }^{9}$ FGV. Exame de Ordem em números. 2013. p. 30. Disponível em: <www.fgv.br/fgvprojetos> Acesso em 21/05/17.

${ }^{10}$ GRAU, Eros Roberto. A ordem econômica na constituição federal de 1988. São Paulo:Malheiros,2015. P.127.

Revista de Pesquisa e Educação Jurídica | e-ISSN: 2525-9636 | Brasília | v. 3 | n. 1 | p. 80 - 97 | Jan/Jul. 
qualificação para o trabalho, conforme previsão constitucional. A educação é direito do cidadão e dever do Estado, portanto a iniciativa privada está sujeita à regularização e fiscalização por parte deste, nos termos da Lei 9.394/96 e Decreto 5.773/06.

As relações contratuais firmadas entre as instituições de ensino superior e alunos estão escoradas nos princípios da boa-fé objetiva e da confiança, de modo que a prestação de serviços educacionais deve ser cumprida de modo a satisfazer o que razoavelmente dela se espera, com a devida adequação e prestabilidade.

\title{
2. As missões das Instituições de Ensino Superior no Brasil
}

Estabelecimentos de ensino privados concretizam sua função social por meio da prestação de serviços de grande relevância social, pois fomenta a empregabilidade ao qualificar seus discentes a fim de habilita-los para o mercado de trabalho, gera empregos, recolhe tributos, fomenta o avanço tecnológico, por meio do incentivo à educação e pesquisa.

Desse modo, possuem munus público, de maneira a garantir o cumprimento de do mister da educação, sendo esta fio condutor que impulsiona o desenvolvimento econômico e social do país.

Nesse sentido, afirma GOMES, Magno Federici ${ }^{11}$ :

\begin{abstract}
Em sentido equivalente, a Declaração Mundial sobre Educação Superior no Século XXI: visão e ação, da UNESCO (1998), mostra o ensino superior como sendo o cume do sistema educacional e um serviço público de relevante valor social, pois promove a ação humana a níveis mais elevados. Como consequência, questões axiológicas derivam do ordenamento jurídico como um todo, determinando obrigações sociais às universidades, desvinculadas do mercado, pois a iniciativa privada pode assumir, com êxito, as matérias inerentes à oferta e à procura.
\end{abstract}

A educação está diretamente conjugada com o desenvolvimento e, portanto, as instituições de ensino superior devem observar o desdobramento de suas atividades como empresas sustentáveis, observando os aspectos econômicos, sociais e ambientais.

Neste sentido, sua missão é ponto a se destacar, de modo que, ao dar cumprimento à formação do indíviduo por meio da educação, o ambienta acadêmico é local apropriado para debates de maneira a conduzir o indivíduo à consciência social e de que ele pode ser agente ativo na sociedade por meio de escolhas responsáveis e pelo sufrágio universal. Ressalte-se

${ }^{11}$ GOMES, Magno Federici. Educação superior privada como serviço de utilidade pública. Ensaio: aval. pol. públ. Educ., Rio de Janeiro, v. 17, n. 63, p. 263-292, abr./jun. 2009. Disponível em $<<$ http://www.scielo.br/pdf/ensaio/v17n63/v17n63a05.pdf > Acesso em 02/01/2017

Revista de Pesquisa e Educação Jurídica | e-ISSN: 2525-9636 | Brasília | v. 3 | n. 1 | p. 80 - 97 | Jan/Jul. 2017. 
que a educação é forma perdurável e infalível de se vindicar que o Estado e a sociedade executem os preceitos solidários da Constituição Federal, visando o desenvolvimento.

O Decreto 5.773 de 2006 quanto à constituição da organização das instituições de ensino superior, em seu artigo 12 estabelece $^{12}$ :

\footnotetext{
Art. 12. As instituições de educação superior, de acordo com sua organização e respectivas prerrogativas acadêmicas, serão credenciadas como:

I - faculdades;

II - centros universitários; e

III - universidades.

Art. 13. O início do funcionamento de instituição de educação superior é condicionado à edição prévia de ato de credenciamento pelo Ministério da Educação.

§ 1o A instituição será credenciada originalmente como faculdade.

$\S 20$ O credenciamento como universidade ou centro universitário, com as conseqüentes prerrogativas de autonomia, depende do credenciamento específico de instituição já credenciada, em funcionamento regular e com padrão satisfatório de qualidade.

§ 3o O indeferimento do pedido de credenciamento como universidade ou centro universitário não impede o credenciamento subsidiário como centro universitário ou faculdade, cumpridos os requisitos previstos em lei.

$\S 4$ o O primeiro credenciamento terá prazo máximo de três anos, para faculdades e centros universitários, e de cinco anos, para universidades.
}

Observe-se que as instituições de ensino superior nascem como faculdades, podendo realizar posteriormente seu credenciamento específico, de modo a tornar-se centro universitário ou universidade. Caso haja indeferimento de seu pedido para credenciamento de universidade, alternativamente poderá apresentar credenciamento subsidiário como centro universitário ou faculdade.

Faculdades isoladas ou integradas buscam a qualificação para o trabalho, ofertando cursos de bacharelado ou licenciaturas, ou ainda, cursos de tecnologia. Nos termos do art. $3^{\circ}$, III da Lei 10.861 de 2004, por meio de sua função social, alcançam os objetios da inclusão social, do desenvolvimento econômico e social, à defesa do meio ambiente, da memória cultural, da produção artística e do patrimônio cultural. ${ }^{13}$

Ressalte-se que as universidades têm a característica conferida pelo texto constitucional de indissociabilidade entre ensino, pesquisa e extensão, conforme art. 207 da Constituição Federal, bem como pelo art. 52 da LDB - Lei no 9.394, de $1996^{14}$ :

12 http://www.planalto.gov.br/ccivil_03/ ato2004-2006/2006/decreto/d5773.htm acesso em 03/8/2015.

13 A função social das IES de pequeno porte e as avaliações do MEC. Celso Frauches. Disponível em: http://blog.abmes.org.br/?p=3863 acesso 03/08/2015

${ }^{14} \mathrm{http://portal.mec.gov.br/arquivos/pdf/ldb.pdf}$ acesso em 03/08/2015

Revista de Pesquisa e Educação Jurídica | e-ISSN: 2525-9636 | Brasília | v. 3 | n. 1 | p. 80 - 97 | Jan/Jul. 2017. 
Art. $52^{\circ}$. As universidades são instituições pluridisciplinares de formação dos quadros profissionais de nível superior, de pesquisa, de extensão e de domínio e cultivo do saber humano, que se caracterizam por:

I - Produção intelectual institucionalizada mediante o estudo sistemático dos temas e problemas mais relevantes, tanto do ponto de vista científico e cultural, quanto regional e nacional;

II - Um terço do corpo docente, pelo menos, com titulação acadêmica de mestrado ou doutorado;

III - Um terço do corpo docente em regime de tempo integral.

Parágrafo único. É facultada a criação de universidades especializada por campo do saber.

Os centros universitários, devem desenvolver ensino de excelência, cumprindo ressaltar que em face das universidades, pode apresentar menor número de docentes, conforme Decreto 5.786 de $2006^{15}$, que dita:

Art. 1o Os centros universitários são instituições de ensino superior pluricurriculares, que se caracterizam pela excelência do ensino oferecido, pela qualificação do seu corpo docente e pelas condições de trabalho acadêmico oferecidas à comunidade escolar.

Parágrafo único. Classificam-se como centros universitários as instituições de ensino superior que atendam aos seguintes requisitos:

I - Um quinto do corpo docente em regime de tempo integral; e

II - Um terço do corpo docente, pelo menos, com titulação acadêmica de mestrado ou doutorado.

Art. 2o Os centros universitários, observado o disposto no Decreto no 5.773, de 9 de maio de 2006, poderão criar, organizar e extinguir, em sua sede, cursos e programas de educação superior, assim como remanejar ou ampliar vagas nos cursos existentes, nos termos deste Decreto.

Ante o texto legal, observa-se que os centros universitários desfrutam da autonomia universitária, conferida às universidades, que traz em seu conceito a autonomia e o estímulo da experimentação, ensaio e renovação, conferindo à universidade a criação de cursos, contratação de professores estrangeiros, emissão de diplomas e sua indissociabilidade se fundamenta no tripé ensino, pesquisa e extensão. No entanto, ao ser atribuída aos centros universitários, possui exigências mais amenas no sentido de apenas ser composta de um quinto do corpo docente em tempo integral, enquanto a universidade é um terço.

Ao tratar-se da gestão da instituição de ensino superior, com a finalidade de estabelecer sua responsabilidade social das IES, independente de sua organização administrativa, aplica-se a teoria da pirâmide de $\mathrm{Carrol}^{16}$, cujo princípio basilar é a

${ }^{15}$ http://www.planalto.gov.br/ccivil 03/_Ato2004-2006/2006/Decreto/D5786.htm acesso em 03/08/2015.

${ }^{16}$ CAVALCANTI, Thais Novaes. Ética empresarial: fundamentos constitucionais de uma ordem econômica e socialmente responsável. Disponível em:

<<http://www.academus.pro.br/professor/thaisnovaes/material/Texto_\%C3\%89tica\%20empresarial_Thais\%20N ovaes\%20Cavalcanti_Academus.pdf $>$ acesso em 03/08/2015. 
responsabilidade econômica, que implica na geração do lucro e o relacionamento entre investidores e funcionários. No segundo patamar da pirâmide encontramos a reponsabilidade legal, no que diz respeito à constituição das instituições de ensino privado, diante da legislação regulatória, fiscalizadora e sancionadora, bem como no que tange aos tributos, meio ambiente, legislação trabalhista, consumerista, civilista, bem como pelo preceito constitucional pela educação de qualidade. No terceiro patamar encontramos a responsabilidade ética, pautada pela função social, sua importância e contribuição para a comunidade, primando pela transparência e pelo cumprimento de sua missão educacional. E, por fim, no topo da pirâmide, temos a responsabilidade filantrópica ou, também chamada, responsabilidade discricionária, que como resultado da agregação dos três anteriores, contribui para a melhoria da comunidade em que se insere e para o bem comum ${ }^{17}$.

Nesse sentido, visando cumprir sua missão formadora, as instituições de ensino superior não devem se restringir à formação técnica para atendimento das demandas mercadológicas, mas também no sentido de preparar o indivíduo para o exercício da cidadania, como fruto da construção do conhecimento integrado, trazendo a consciência de de que se faz parte de um todo, ou seja, a sociedade, e tornando-o capaz de tomar decisões responsáveis, derivadas da liberdade e da autonomia conquistadas neste processo emancipador.

Desse modo, observa-se que sua missão é a caracterizada pelo exercício de promover a reflexão e o pensamento crítico, propor mudanças para construção de um mundo melhor, no cumprimento de suas responsabilidades, com o claro objetivo de fomentar a educação para o desenvolvimento sustentável.

\section{A qualidade na prestação de serviços jurídicos educacionais}

O ensino com padrão de qualidade é preceito constitucional. Logo, a prestação de serviços educacionais na área jurídica também deve atender ao princípio constitucional do padrão de qualidade.

Como matéria de relevância públicam, a educação com padrão de qualidade integra de variáveis que compõem o fenômeno, tais como os aspectos econômicos, pedagógicos e

\footnotetext{
${ }^{17}$ Lourenço, Valéria Jabur Maluf Mavuchian. Direito à educação e sustentabilidade: a complementariedade entre o ensino superior jurídico público e privado. 2017. 117f. Dissertação (Mestrado em Direito) Universidade Nove de Julho, São Paulo, 2017. p. 54
}

Revista de Pesquisa e Educação Jurídica | e-ISSN: 2525-9636 | Brasília | v. 3 | n. 1 | p. 80 - 97 | Jan/Jul. 2017. 
administrativos. É possível aplicar-se, inclusive, definições teóricas de administração empresarial, a fim de se averiguar o padrão de qualidade educacional.

O mandamento qualidade, no contexto da globalização, tem sido o objeto de empresas no mundo e a educação também concorre para este alvo. Como instrumento de divulgação da cultura e de preparo para participação no sistema econômico, social e político, a busca pelo desenvolvimento integral e a capacitação para a cidadania, pode-se valer de métodos e técnicas, por vezes utilizadas na administração no sistema educacional. Nesse sentido, afirma José Eustáquio Romão ${ }^{18}$ :

\footnotetext{
Várias nações do mundo, mesmo no conjunto das mais desenvolvidas, têm se preocupado com a qualidade da educação dispensada regularmente às suas crianças e adolescentes, quando se percebem ultrapassadas por outras, no quadro de uma economia mundializada e extremamente competitiva.
}

A qualidade dos cursos deve possuir excelência, aferível tanto nos resultados decorrentes das avaliações a que a instituição é submetida, quanto na efetiva integração dos discentes no mercado de trabalho.

Ao se tratar do bom desempenho da instituição de ensino, citamos fatores que o compõem, quais sejam, o saber básico sistematizado, a combinação de ciência, tecnologia avançada e grandes investimentos, considerados insumos oferecidos à escola, como indicadores de qualidade, bem como qualificação docente política salarial aplicada aos professores, a infraestrutura do estabelecimento, o material didático disponível, os métodos e as técnicas de ensino adotados, sendo os verdadeiros fatores intervenientes no processo de ensino-aprendizagem.

Considerando uma leitura crítica das habilidades e competências a fim de se aferir o padrão de qualidade de ensino, ainda vige na sociedade o caráter mercadológico da educação superior. Corroboram nesse sentido Ronaldo Porto Macedo Júnior e Ana Cristina Braga Martes $^{19}$, ao afirmarem:

A educação jurídica num mundo globalizado deve se concentrar não apenas em criar os
meios mediante os quais os objetivos e propósitos modernizadores acima enumerados
possam ser atingidos, mas também para a própria escolha dos propósitos a serem
alcançados. Ela requer a criação e reinvenção de novos propósitos para ela mesma.
Uma das funções de uma faculdade de direito enquanto núcleo de conhecimento
jurídico é não apenas responder a demandas do mercado e do estado, mas também
imaginar e criar novos objetivos capazes de forjar o próprio sentido da educação
jurídica. Desse modo, as escolas de direito devem ser vistas, ao menos em parte, como

${ }^{18}$ ROMÃO, José Eustáquio. Avaliação Dialógica: desafios e perspectivas. São Paulo, 1998. p. 7.

${ }^{19}$ Junior, Ronaldo Porto Macedo; Martes, Ana Cristina Braga. Ensinar direito: o sentido de criar sentidos. Cadernos FGV Direito Rio - Educação e Direito, Rio de Janeiro: 2014, volume 09, p. 65-80. 
instituições autorreflexivas, ou seja, que examinam e criam os seus próprios sentidos.

Em face da expansão universitária por meio da iniciativa privada, ao se propor maior acesso à educação superior no país, passou-se a operar uma produtividade de formandos, em um sistema progressivamente de padrão de qualidade questionável, posto o ensino reduzir-se estritamente ao tecnicismo, relevando o caráter emancipador que a educação possui, trazendo concluintes despreparados para elementares desempenhos desejáveis oriundo dos cursos superiores, e, especificamente dos cursos jurídicos ${ }^{20}$.

O ensino jurídico deve conferir a possibilidade do desenvolvimento do pensamento jurídico a fim de se resolver problemas, realizar análise e raciocínio jurídico, promoção da pesquisa jurídica, capacitar para negociações, habilitar para procedimentos contenciosos, organizar o trabalho jurídico e, por fim reconhecer e solucionar questões éticas. Tais competências desenvolvidas no curso de educação jurídica, habilitam o bacharel, no contexto do mercado atual ${ }^{21}$.

Nesse mesmo entendimento, destacam Ronaldo Porto Macedo Júnior e Ana Cristina Braga Martes ${ }^{22}$ :

Acreditamos que há duas estratégias importantes. Em primeiro lugar, é necessário incluir no ensino do direito uma discussão sistemática sobre seu signifi cado do e das profi ssões jurídicas num mundo globalizado. Em segundo lugar, é essencial discutir o signifi cado das responsabilidades individuais e coletivas e a natureza da ética produzida pela globalização. Estas incluem questões relacionadas à ética profissional, bioética, proteção ambiental, cidadania global, desigualdades regionais, acesso à informação e direitos, desigualdades, democracia, etc.

É importante também destacar que a função das escolas de direito não deve se limitar a preparar técnica e tecnologicamente o profissional para bem desempenhar suas funções no mercado de trabalho. Além disto, elas devem também produzir reflexão sobre o próprio sentido do direito e da construção de uma vida no direito num mundo globalizado.

Em particular, o curso de direito está sujeito à dupla avaliação, ou seja, além da fiscalização regulamentada pelos órgãos do Ministério da Educação, é avaliado pela Ordem dos Advogados do Brasil - OAB, por meio do programa OAB Recomenda. A fim de participar desta avaliação, as instituições de ensino jurídico devem ter participado dos Exames de Ordem

\footnotetext{
${ }^{20}$ Lourenço, Valéria Jabur Maluf Mavuchian. Direito à educação e sustentabilidade: a complementariedade entre o ensino superior jurídico público e privado. 2017. 117f. Dissertação (Mestrado em Direito) -

Universidade Nove de Julho, São Paulo, 2017. p. 89.

${ }^{21}$ Idem, p. 90.

22 Junior, Ronaldo Porto Macedo; Martes, Ana Cristina Braga. Ensinar direito: o sentido de criar sentidos. Cadernos FGV Direito Rio - Educação e Direito, Rio de Janeiro: 2014, volume 09, p. 65-80.
} 
unificados avaliados e ter tido 20 inscritos, pelo menos, em cada um. Cruzam-se os resultados do Enade e do Exame de Ordem Unificado, e do resultado obtido se confere selo de qualidade ou reprova-se o curso jurídico da instituição de ensino superior submetida à avaliação. ${ }^{23}$

Com base no estudo "Exame de Ordem em Números", resultado da parceria entre a Ordem dos Advogados do Brasil (OAB) e a Fundação Getúlio Vargas (FGV Projetos), unidade de pesquisa aplicada e de assessoria técnica da Fundação Getúlio Vargas, responsável pela organização do Exame de Ordem Unificado desde a sua segunda edição em 2010, tendo como referência os exames unificados II a X, observa-se uma variação de $11 \%$ a $27 \%$ de aprovação dos inscritos no exame ${ }^{24}$.

A insuficiência dos cursos jurídicos leva à óbvia reprovação nos exames da Ordem dos Advogados do Brasil, e algumas razões podemos mencionar, tais como, o baixo nível do corpo docente e do corpo discente; o ensino secundário pouco serve após o ingresso do estudante na faculdade, sendo negligenciado também; a proliferação do mercantilismo do ensino jurídico e o estado caótico da maioria das escolas brasileiras de primeiro e segundo $\operatorname{grau}^{25}$.

Cumpre ressaltar a importância da $\mathrm{OAB}$ na criação de cursos de direito, devendo previamente se manifestar antes da autorização do Ministério da Educação, nos termos da Estatuto da Ordem dos Advogados do Brasil, Lei 8.906/94, artigo 54, sendo certo que ambos trabalham em parceria a fim de aperfeiçoar o ensino jurídico sem perda das autonomias e competências $^{26}$. Não obstante, a capacidade para o exercício profissional também é de competência deste órgão ${ }^{27}$.

Por outro lado, ao propagar que IES aprova grande número de seus formandos na $\mathrm{OAB}$, produz repercussão mercadológica para a instituição de modo a trazer uma imagem positiva e credibilidade a fim de atrair alunos, em uma analogia às marcas de certificação que certificam um padrão de qualidade para produtos ou serviços, alcançando maior número de

\footnotetext{
${ }^{23}$ Disponível em: $<<$ http://www.oab.org.br/arquivos/pdf/Geral/Programa_OAB_Recomenda.pdf $\gg$ Acesso em 03/08/2015.

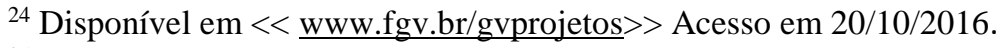

${ }^{25}$ ADEODATO, João Maurício. A OAB e a massificação do ensino jurídico. IN: SILVEIRA, Vladmir Oliveira da; NASPOLINI-SANCHES, Samyra H.D.F; COUTO, Mônica Bonetti. Educação Jurídica. São Paulo: Saraiva, 2013.p.567

${ }^{26}$ GELLER, Rodolfo Hans. Instrumentos de avaliação para autorização, reconhecimento e aumento de vagas dos cursos jurídicos. IN: SILVEIRA, Vladmir Oliveira da; NASPOLINI-SANCHES, Samyra H.D.F; COUTO, Mônica Bonetti. Educação Jurídica. São Paulo: Saraiva, 2013.p. 454 - 457

${ }^{27}$ Lourenço, Valéria Jabur Maluf Mavuchian. Direito à educação e sustentabilidade: a complementariedade entre o ensino superior jurídico público e privado. 2017. 117f. Dissertação (Mestrado em Direito) Universidade Nove de Julho, São Paulo, 2017. p. 91.
} 
consumidores de seus produtos e serviços ${ }^{28}$.

O Ministro Ricardo Lewandowski, presidente do STF, em cerimônia de entrega do selo OAB Recomenda ${ }^{29}$ a 142 faculdades de direito em 2016, ao abordar em seu discurso a importância de boas faculdades formarem bacharéis em direito, afirmou que esta formação deve ser ampla e multicultural, focada em diversas áreas do conhecimento, permitindo um avanço em políticas que serão essenciais no futuro do país, tais como a diminuição da litigiosidade, com métodos alternativos de resolução de conflitos, como mediação, conciliação e arbitragem, e as audiências de custódia ${ }^{30}$.

Ressaltou os operadores do direito devem ter uma visão crítica e alternativa de sua prática, devendo estas IES formar bacharéis aptos para utilização de métodos alternativos, contribuindo para a pacificação do país e a preservação do Estado de Direito, patrimônio inalienável de todos os cidadãos ${ }^{31}$.

No entanto, observa-se que das 142 IES recomendadas, 72 são públicas e 70 são privadas, sendo distribuídas da seguinte forma: Região Norte: 10 públicas e 1 privada, Região Nordeste: 26 públicas e 11 privadas, Região Centro-Oeste: 9 públicas e 3 privadas, Região Sudeste: 16 públicas e 39 privadas, Região Sul: 11 públicas e 16 privadas.

Tendo como referência o selo $\mathrm{OAB}$ Recomenda, no que tange à qualidade, observamos que apenas 142 IES foram recomendadas, sendo praticamente metade públicas e metade privadas.

Cumpre observar que das 142 IES recomendadas, a OAB usou como critério não somente a identificação da IES, mas especificou o campus, de modo que uma mesma IES aparece mais de uma vez, devido à especificação da unidade de sua localidade.

Em contrapartida, no ano de 2016, no site do Ministério da Educação ${ }^{32}$ consta que o número de IES que ofertam o curso de Direito em todo o Brasil, entre públicas e privadas, totaliza a quantia de 945 , sem especificar campus.

Nesse sentido, uniformizando o selo OAB recomenda pelo critério do MEC quanto

\footnotetext{
${ }^{28}$ Idem, p. 91.

${ }^{29} \mathrm{O}$ selo de qualidade OAB Recomenda refere-se ao reconhecimento pela entidade destinado às IES pela excelência no ensino do direito. O selo é entregue a cada três anos e leva em conta a aprovação de alunos no Exame de Ordem e o seu desempenho no Enade (Exame Nacional de Desempenho dos Estudantes).

${ }^{30}$ Idem p.92.

${ }^{31}$ Disponível em: << http://www.oab.org.br/noticia/29187/oab-entrega-a-142-faculdades-selo-de-qualidade-emensino-de-direito > Acesso em 19/11/2016

32 MEC, Instituições de Educação Superior e Cursos Cadastrados, Disponível em: <http://emec.mec.gov.br/>, acesso em 05/01/2016.
}

Revista de Pesquisa e Educação Jurídica | e-ISSN: 2525-9636 | Brasília | v. 3 | n. 1 | p. 80 - 97 | Jan/Jul. 
às IES que ofertam curso de Direito no Brasil, sem discriminar campus, pode-se considerar apenas 124 IES, sendo 60 públicas e 64 privadas, ou seja, 13,1\% das IES, sendo 6,33\% públicas e 6,67\% privadas, em face das 945 situadas no território brasileiro. Desse modo, torna-se evidente que, pelo viés da aprovação na $\mathrm{OAB}$, como forma de propor uma formação com qualidade para o bacharel em direito, visando o mercado de trabalho, em face da complementariedade entre ensino superior público e privado, o índice é muito baixo e insatisfatório, demonstrando que a missão das instituições de ensino superior e o mister do direito à educação de qualidade ainda sofrem percalços e a e nestas instituições não tem sido primada por seus princípios ${ }^{33}$.

Neste sentido, as instituições de ensino superior na área jurídica devem proporcionar a possibilidade de desenvolver o pensamento jurídico, como tecem a respeito Ronaldo Porto Macedo Júnior e Ana Cristina Braga Martes ${ }^{34}$ :

Dentre os propósitos básicos, sobre os quais há pouco desacordo, é possível listar o de de modo a formar advogados proficientes no trato com questões relacionadas à nova dinâmica do mercado, estado e sociedade em geral. Evidentemente este conjunto de habilidades e capacidades requer um treinamento complexo e interdisciplinar, tanto nas disciplinas da dogmática jurídica tradicional como também em outras ligadas à filosofia e às ciências sociais como economia, administração, contabilidade, ciência política, sociologia, etc.

Esta observação nada tem de muito original, à medida que sugere a combinação de objetivos bem tradicionais como o aprendizado da prática jurídica através de estágios, ensino do direito formal positivado ("black-letter" law), ensinar o aluno a "pensar juridicamente" ("think like a lawyer"), e o ensino do direito como uma "ciência do direito". Ao lado de tais propósitos, se associam novos propósitos como o ensino do direito como política (no sentido de policy, e não apenas como ciência), e as políticas como um suplemento para a educação tradicional, que assume um caráter mais instrumental e técnico. Por fim, ainda se poderia incluir o desenvolvimento da capacidade de compreender o funcionamento do estado segundo modelos econômicos ou modelos inspirados na ciência política e na filosofia política.

$\mathrm{O}$ jurista que o mundo contemporâneo requer, em especial o advogado, precisa ter novas habilidades para rapidamente aprender informações, técnicas e conhecimento. Ele deve também ser treinado para ser capaz de solucionar problemas e pensar e desenhar novos arranjos institucionais capazes de atingir novos objetivos econômicos e sociais. Ao lado deste conjunto de propósitos relativamente pouco polêmicos, seria também possível agregar outros objetivos menos consensuais defendidos por alguns teóricos. Dentre eles, pode-se citar a ampliação do estudo do direito enquanto objeto moral, e não apenas como objeto de conhecimento científico, o ensino das perspectivas críticas sobre o direito, e ainda o treinamento de ativistas sociais orientados para a transformação social.

A formação do bacharel em Direito deve primar pela análise e o raciocínio jurídico,

\footnotetext{
${ }^{33}$ Lourenço, Valéria Jabur Maluf Mavuchian. Direito à educação e sustentabilidade: a complementariedade entre o ensino superior jurídico público e privado. 2017. 117f. Dissertação (Mestrado em Direito) Universidade Nove de Julho, São Paulo, 2017. p. 93.

${ }^{34}$ Junior, Ronaldo Porto Macedo; Martes, Ana Cristina Braga. Ensinar direito: o sentido de criar sentidos. Cadernos FGV Direito Rio - Educação e Direito, Rio de Janeiro: 2014, volume 09, p. 65-80.
} 
capacitando-o para negociações corriqueiras, habilitando-o para os procedimentos contenciosos, levando-o a reconhecer soluções por meio de questões éticas.

\section{Conclusão}

A qualidade do ensino jurídico no país tem se destacado, por vezes, como insuficiente. Tal fato pode ser constatado a partir dos resultados obtidos no Exame Unificado da $\mathrm{OAB}$ e à atribuição do Selo OAB recomenda às instituições de ensino superior.

A formação do operador do direito deve ir além do conhecimento da lei, mas deve abranger conhecimentos sociais, políticos, econômicos e de administração, expandindo sua visão, contextualizando-a num mercado global.

A formaçãoo jurídica deve ultrapassar a meta da simples aprovação no exame da $\mathrm{OAB}$, mas efetivamente habilitar o bacharel como futuro operador do Direito, trazendo-lhe a amplitude de conhecimento, com formação interdisciplinar compondo uma base sólida a fim de formar o estudante qualificado e apto para o exercício da profissão.

Mais do que questionar, pensar num sistema de ensino que seja um pouco melhor que uma linha de produção, onde o único objetivo é a obtenção de um diploma, é fato que se deve avaliar, diante da cobrança da sociedade e do mercado de trabalho, que no contexto da globalização, requer a formação de cidadãos capacitados e conscientes, realmente aptos ao exercício de seu mister.

Como forma de se verificar a efetividade do direito à educação, como direito fundamental, de modo a se dar cumprimento ao estabelecido no artigo 205 da Constituição Federal, o graduando dos cursos jurídicos, atualmente no Brasil, em virtude da expansão universitária, que conferiu grande demanda para o curso do Direito, observamos no decorrer do trabalho que não tem sido contemplado de forma satisfatória.

Foi utilizado como referencial o índice de aprovação o Exame Nacional da OAB, por meio de índices de aprovação do Selo $\mathrm{OAB}$ recomenda a fim de verificar a efetiva habilitação para o trabalho da cidadania tendo por referência o trabalho Exame de Ordem em Números, resultado da parceria entre a OAB e a FGV Projetos.

A formação do operador do direito deve ir além do conhecimento da lei, devendo abranger conhecimentos sociais, políticos, econômicos e de administração, expandindo sua 
visão, contextualizando-o num mercado global. Deve ultrapassar a meta da aprovação no exame da $\mathrm{OAB}$, visando efetivamente habilitar para formação do futuro operador do direito, trazendo-lhe a amplitude de conhecimento, com formação interdisciplinar compondo uma base sólida a fim de formar o estudante qualificado e apto para o exercício da profissão.

\section{Referências}

ADEODATO, João Maurício. A OAB e a massificação do ensino jurídico. IN: SILVEIRA, Vladmir Oliveira da; NASPOLINI-SANCHES, Samyra H.D.F; COUTO, Mônica Bonetti. Educação Jurídica. São Paulo: Saraiva, 2013.

BRASIL, Constituição Federal de 1988. Disponível em: http://www.planalto.gov.br. Acesso em 03/06/2016.

CAVALCANTI, Thais Novaes. Ética empresarial: fundamentos constitucionais de uma ordem econômica e socialmente responsável. Disponível em: <<http://www.academus.pro.br/professor/thaisnovaes/material/Texto_\%C3\%89tica\%20empre sarial_Thais\%20N ovaes\%20Cavalcanti_Academus.pdf $>>$ acesso em 03/08/2015.

CHAUI, Marilena. Convite à Filsofia. São Paulo: Ática, 2000.

FGV. Exame de Ordem em números. 2013. p. 30. Disponível em: 〈www.fgv.br/fgvprojetos〉 Acesso em 21/05/17.

GELLER, Rodolfo Hans. Instrumentos de avaliação para autorização, reconhecimento e aumento de vagas dos cursos jurídicos. IN: SILVEIRA, Vladmir Oliveira da; NASPOLINISANCHES, Samyra H.D.F; COUTO, Mônica Bonetti. Educação Jurídica. São Paulo: Saraiva, 2013.

GOMES, Magno Federici. Educação superior privada como serviço de utilidade pública. Ensaio: aval. pol. públ. Educ., Rio de Janeiro, v. 17, n. 63, p. 263-292, abr./jun. 2009. Disponível em $<$ http://www.scielo.br/pdf/ensaio/v17n63/v17n63a05.pdf $\gg$ Acesso em 02/01/2017.

GRAU, Eros Roberto. A ordem econômica na constituição federal de 1988. São Paulo: Malheiros, 2015.

JUNIOR, Ronaldo Porto Macedo; MARTES, Ana Cristina Braga. Ensinar direito: o sentido de criar sentidos. Cadernos FGVDIREITORIO, Educação e Direito - Volume 09 - 2014.

KIM, Richard Pae. BOLZAM, Angelina Cortelazzi. Direito à educação de qualidade e seus fundamentos jurídicos. Cadernos de Direito, Piracicaba, v. 15, jul-dez 2015, p. 177. Disponível em: << http://dx.doi.org/10.15600/2238-1228/cd.v15n29p167-200〉> Acesso em 22/11/2016. 
LOURENÇO, Valéria Jabur Maluf Mavuchian. Direito à educação e sustentabilidade: a complementariedade entre o ensino superior jurídico público e privado. 2017. 117f. Dissertação (Mestrado em Direito) - Universidade Nove de Julho, São Paulo, 2017.

MEC, Instituições de Educação Superior e Cursos Cadastrados, Disponível em: $<$ http://emec.mec.gov.br/>, acesso em 05/01/2016.

FRAUCHES, Celso. A função social das IES de pequeno porte e as avaliações do MEC. Disponível em: http://blog.abmes.org.br/?p=3863 acesso 03/08/2015.

ONU - Organização das Nações Unidas. Declaração Universal dos Direitos Humanos. 10 dez. 1948. Disponível em: http://www.ohchr.org/EN/UDHR/Pages/Language.aspx?LangID=por. Acesso em: 22/11/2016.

ROMÃO, José Eustáquio. Avaliação Dialógica: desafios e perspectivas. São Paulo, 1998.

SILVA, José Afonso da. Curso de Direito Constitucional Positivo. São Paulo: Malheiros, 2004.

SILVEIRA, Vladmir Oliveira da; ROCASOLANO, Maria Mendez. Direitos Humanos: conceitos, significados e funções. São Paulo: Saraiva. 2010.

SILVEIRA, Vladmir Oliveira da; SANCHES, Samyra Haydêe Dal Farra Naspolini Sanches; COUTO, Mônica Bonetti. Educação Jurídica. São Paulo: Saraiva, 2013.

http://www.planalto.gov.br/ccivil_03/_ato2004-2006/2006/decreto/d5773.htm Acesso em 03/8/2015.

http://portal.mec.gov.br/arquivos/pdf/ldb.pdf acesso em 03/08/2015.

http://www.planalto.gov.br/ccivil_03/_Ato2004-2006/2006/Decreto/D5786.htm Acesso em 03/08/2015.

http://fgvprojetos.fgv.br/sites/fgvprojetos.fgv.br/files/exame_de_ordem_em_numeros.pdf. Acesso em 20/10/2016. 